\section{Pedro Mendiola Oñate}

Subdirector del Área de América Latina de la Biblioteca Virtual Miguel de Cervantes Saavedra. Ha centrado su actividad investigadora en la poesía argentina de vanguardia, tema al que ha dedicado diversos trabajos críticos, entre los que destaca el libro Buenos Aires entre dos calles: breve panorama de la vanguardia poética argentina (2001). Ha colaborado en la edición electrónica de Nuevos textos para la Literatura Hispanoamericana colonial (2000).

\title{
FICCIONES FUNDACIONALES EN LA NARRATIVA ARGENTINA DEL SIGLO XX
}

\author{
PEDRo MENDiola OÑate
}

Supuesta, pues, la incertidumbre de la historia, vuelvo a decir, se debe preferir la lectura y estudio de la fábula, porque siendo ella parte de una imaginación libre y desembarazada, influye y deleita más.

Concolorcorvo

1

Palabras de Tomás Eloy Martínez en Marily Martínez-Richter (ed.), La caja de la escritura. Diálogos con narradores y críticos argentinos, Frankfurt / Madrid, Vervuert / Iberoamericana, 1997, pág. 39.

2

Leopoldo Zea, «Prólogo» a Pensamiento positivista latinoamericano, Caracas, Biblioteca Ayacucho, tomo I, págs. XVIII-XXI.

3

Cf. Andrés Bello, "Modo de estudiar la historia", publicado en El Araucano, núm. 913, Santiago, 4 de febrero de 1848; en Obras Completas, v. XXIII, Caracas, Fundación La Casa de Bello, 1981, pág. 249.

4

Cf. Carlos M. Rama, Historia de las relaciones entre España y la América Latina. Siglo XIX, Madrid, Fondo de Cultura Económica, 1982.

Ficciones fundacionales en la narrativa argentina del siglo $\mathrm{XX}$ PEDRO MENDIOLA OÑATE
En una reunión de escritores y críticos argentinos celebrada en abril de 1993, Tomás Eloy Martínez argumentaba que había observado una obturación, una «censura deliberada» de los orígenes argentinos, de la que sólo se salvan un par de títulos: «el tratado de Ruy Díaz de Guzmán que da nombre al país, La Argentina $M a-$ nuscrita, publicado a comienzos del siglo XVII, y Viaje al Río de la Plata, del alemán Ulrico Schmidl, que apareció en Frankfurt en 1567». Tomás Eloy Martínez fundamentaba esta afirmación en un estudio de Nicolas Shumway titulado La invención de Argentina. La tesis de Shumway proponía una ruptura, un antes y un después, en el seno de la historia argentina que parte de la célebre Historia de Belgrano (1857) de Bartolomé Mitre, en la que se establecía la fecha de la independencia como nacimiento cronológico de la nación argentina: «Quienes han nacido antes, no son argentinos» ${ }^{1}$.
5 Leopoldo Lugones, El imperio jesuítico, (1.9 ed. 1904), en Obras en prosa, México, Aguilar, 1962, pág. 82.

6

Andrés Bello, op. cit., p. 251. Debe de referirse al historiador español Antonio Solís y Riva- deneira (Historia de la conquista de México, población y progresos de la América septentrional, conocida por el nombre de Nueva España, Madrid, Bernardo de Villa-Diego, 1685), y al británico William Robertson (The History of America, London, 1777, 2 vols.).
Indudablemente, tanto Shumway como Tomás Eloy Martínez llevan su parte de razón. Tras los distintos procesos de independencia, se establece en las nuevas naciones americanas un período de revisión histórica, lance que Leopoldo Zea ha caracterizado como una «crítica de la realidad heredada $»^{2}$. La afirmación de las diversas identidades nacionales, esa «independencia del pensamiento ${ }^{3}$ americano que acuñara Andrés Bello, acarreaba un impulso paralelo de «descolonización» ${ }^{4}$, un «desprendimiento» ${ }^{5}$ lógico que Lugones comparó con el ciclo de la reconquista cristiana en la península ibérica. Sin embargo, esa impugnación del pasado colonial no implicaba necesariamente una negación, como evidencia el propio Andrés Bello en textos como «Modos de estudiar la historia», donde invitaba a «beber en las fuentes», frente a una interpretación foránea de la historia americana:

¿Queréis por ejemplo, saber qué cosa fue el descubrimiento y conquista de América? Leed el diario de Colón, las cartas de Pedro de Valdivia, las de Hernán Cortés. Bernal Díaz del Castillo os dirá mucho más que Solís y que Robertson. Interrogad a cada civilización en sus obras; pedid a cada historiador sus garantías. Esa es la primera filosofía que debemos aprender de la Europa $a^{6}$. 
En el caso argentino, es evidente que la fecha de 1810 marca un punto de inflexión en el seno de la historiografía, y también de la historiografía literaria, y de la propia literatura. Sin embargo, puede decirse que ese sentimiento de ruptura con el pasado, que nace con Mariano Moreno, uno de los héroes de Mayo, y que se extiende a toda la generación del 37 y pervive todavía en Sarmiento y Esteban Echeverría, convive ${ }^{7}$ a lo largo del siglo XIX con un incipiente proceso de reconstrucción crítica de la época colonial, que tuvo entre sus más importantes defensores a Juan María Gutiérrez y a Juan Bautista Alberdi'.

Uno de los casos más significativos de esa reconstrucción lo encontramos curiosamente en la figura controvertida y polémica de Pedro de Angelis, un historiador de origen napolitano, que había llegado a la Argentina en 1827 de la mano del entonces presidente de la República Bernardino Rivadavia. Algunos años después, ya bajo la tiranía de Rosas, emprende el italiano la publicación de una magna recopilación de documentos, editada entre 1835 y 1837, bajo el título de Colección de obras y documentos inéditos, relativos a la bistoria antigua y moderna de las Provincias del Río de la Plata. El objetivo de la colección, según De Angelis, era el de rescatar importantes documentos de la historia americana, que desde España habían sido ignorados, y en la mayoría de los casos despreciados. Entre los más de 60 títulos que componen la obra, encontramos el de la Fundación de la ciudad de Buenos-Aires, por D. Juan de Garay, en cuyo discurso preliminar dice De Angelis:

Los pueblos modernos no tienen que buscar su origen en los poetas y mitólogos: los historiadores son sus genealogistas, y del primer día de su existencia puede hablarse con tanto acierto como de un acontecimiento contemporáneo.

Ya pasaron los tiempos en que para edificar ciudades tenían que bajar los dioses del Olimpo. Estas fábulas, inventadas para lisonjear la vanidad de los pueblos, aumentan el caudal de mentiras que nos han transmitido los antiguos, por más que se empeñen en acreditarlas los eruditos?.

Pero traicionaba a Pedro de Angelis su celo escrupuloso de historiador, porque el espíritu del acto fundacional se construye precisamente sobre una intensa red de ideas, de símbolos, de quimeras y, en última instancia,

de fábulas, que confieren al hecho puramente físico del establecimiento territorial, una profunda significación alegórica. La fundación de ciudades tuvo además una importancia fundamental en el proceso de población y conquista del Nuevo Mundo. Ángel Rama y José Luis Romero han detallado sobradamente las distintas funciones políticas, sociales, religiosas y culturales que desempeñan las ceremonias fundacionales en ese período ${ }^{10}$. El caso de Buenos Aires es especialmente complejo ya que, según cuenta la tradición, la ciudad fue dos veces fundada: por Pedro de Mendoza en 1536 y por Juan de Garay en 1580 . Teniendo en cuenta la distinción que hacía De Angelis respecto a la historia y la fábula, podríamos decir que si Garay aportó el documento, el trazado, la historia; Mendoza había forjado la idea de la ciudad, la fábula.

\section{LA FORMACIÓN DE UNA TRADICIÓN}

Tal cual suceso memorable, corrompido con la alteración que de suyo lleva el tiempo, y la fragilidad de la memoria, conservaban los relacionistas, y lo perpetuaban con el canto. En lo demás de sus vasallos, las hazañas de sus caciques y las de sus mayores se echaban en perpetuo olvido, $y$ apenas los hijos se acordaban de las proezas de sus padres.

José Guevara

7

No olvidemos, como advierte José Ingenieros, que en todo el proceso constitutivo de la $\mathrm{Na}$ ción Argentina, "el pensamiento revolucionario» convive igualmente con la restauración de «las ideas y los sentimientos propios del pensamiento hispano-colonial» (José Ingenieros, La evolución de las ideas argentinas, Buenos Aires, Editorial Futuro, 1961, t. I, págs. 285-291).

8

Esta coexistencia ideológica puede observarse incluso en el curso de una misma publicación: Pedro Luis Barcia, en su Historia de la historiografia literaria argentina. Desde los orígenes hasta 1917 (Buenos Aires, Ediciones Pasco, 1999, págs. 77-87), recoge los textos introductorios de Florencio Varela y Juan Bautista Alberdi al primer certamen poético de Mayo, celebrado en Montevideo en 1841. Mientras Varela escribía en su «Informe»: «Ninguna literatura americana pudo haber mientras duró en estas regiones la dominación de España. Jamás una colonia tuvo ni tendrá literatura propia (...) Alzose el pueblo de la condición de colono a la de soberano; $y$ en el gran sacudimiento nació también la poesía nacional, hermana gemela de la Independencia»; por su parte, Alberdi argumentaba: «E estudio de nuestra literatura colonial sería un digno temo de las investigaciones de los talentos serios que se levantan es tiempo ya de abandonar preocupaciones pasadas de moda, y emprender seriamen- te el examen de los antecedentes literarios, legislativos y administrativos de nuestros tres siglos coloniales, que han dado a luz la sociedad presente; solo en el profundo estudio de nuestro pasado, aprenderemos a apreciar el presente y descubrir la llave del porvenir» (Certamen poético, Montevideo, 25 de mayo de 1841, Imprenta Constitucional del P. P. Olave).

9

Pedro de Angelis, «Discurso preliminar a la Fundación de Buenos Aires», Fundación de la ciudad de Buenos-Aires, por D. Juan de Garay, con otros documentos de aquella época, Buenos Aires, Colección de obras y documentos inéditos, relativos a la historia antigua y moderna de las provincias del Río de la Plata, Imprenta del Estado, 1836, tomo III.

10

CF. Ángel Rama, La ciudad letrada, Hanover, Ediciones del Norte, 1984, págs. 1-20; José Luis Romero, Latinoamérica: las ciudades y las ideas, México, Siglo XXI, 1976, págs. 45-68.

Ficciones fundacionales en la narrativa argentina del siglo $\mathrm{XX}$ PEDRO MENDIOLA OÑATE 


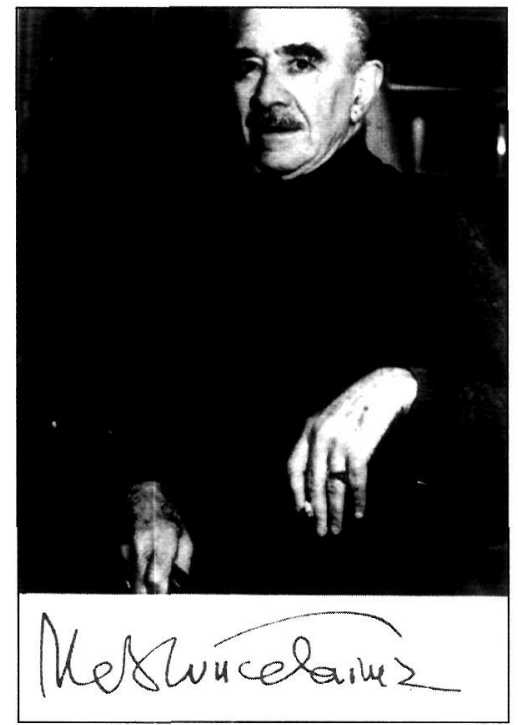

Manuel Mujica Laínez.

11

Cf. Martín del Barco Centenera, Argentina y Conquista del Río de la Plata, con otros acaecimientos de los Reinos del Perú, Tucumán y estado del Brasil, Lisboa, Imp. de Pedro Crasbeek, 1602, fol. IIr.

\section{2}

Ulrich Schmidl, Neuwe Welt, das ist Warhafftige Beschreibung aller Historien von erfindung viler vnbekanten Königreichen, Franckfurt, M. Lechler in verlegung $\mathrm{S}$. Feirabends \& $\mathrm{S}$. Hüters, 1567. La primera traducción castellana es la titulada Historia y descubrimiento del Río de la Plata y Paraguay por Hulderico Schmidel, Madrid, 1749.

\section{3}

La primera edición del Romance de Luis de Miranda la dio a la imprenta Cesáreo Fernández Duro (Arca de Noé, Libro Sexto de las Disquisiciones náuticas, $\mathrm{Ma}$ drid, 1881, pp. 595-600) con el erróneo título, como advierte José Torre Revello, de Luis de Miranda, a la ciudad de Asunción, Provincia del Río de la Plata, recientemente poblada (Cf. Luis de Miranda y Villafaña, Romance, versiones paleográfica y moderna, con noticia preliminar de José Torre Revello, Buenos Aires, Imprenta y Casa Editora «Coni», 1951, pág. 14).

Ficciones fundacionales en la narrativa argentina del siglo $\mathrm{XX}$ PEDRO MENDIOLA OÑATE

Se refería el padre Guevara a la falta de una tradición escrita que perpetuara la historia antigua de los pueblos indígenas. Muy distinta fue, sin embargo, la disposición del conquistador español que, tomando al pie de la letra el proverbio latino verba volant, scripta manent, advirtió prontamente la importancia de «poner en escripto» hasta el más nimio detalle, para que no se viera la memoria «sin razón obscurecida», y para que el mundo tuviera «entera noticia y verdadera relación» ${ }^{11}$ de cuanto acontecía en ese nuevo hito para la Historia que era el descubrimiento y conquista de las tierras del Nuevo Mundo.

14

Centenera, op. cit.

15

La primera edición es la de Pedro de Angelis para su citada Colección de obras y documentos..., con el título de Historia argentina del descubrimiento, población y conquista del Río de la Plata (Tomo I, 1835). Ángel Rosenblat explica que el título original era: «Anales del descubrimiento, población y conquista de las provincias del Río de la Plata. El título que hasta hoy le ha dado la tradición se debe gratuitamente a los copistas e historiógrafos del XVIII, que difundieron los códices, en versiones muy dispares, con enmiendas e interpolaciones por todo el virreinato, y que para emparentarla como fuente histórica, con la Argentina impresa de Centenera, la llamaron "la Argentina manuscrita», y aun simplemente la Argentina de Guzmán» (Ángel Rosenblat, Estudios dedicados a la Argentina, Caracas, Monte Ávila Editores, 1991, Biblioteca Ángel Rosenblat, t. IV, pág. 19)

16

La obra de Lizárraga circuló manuscrita desde su redacción a finales del siglo XVI hasta su definitiva publicación, con el título de La descripción de las Indias, por Carlos A. Romero, Revista histórica del Perú, Lima, 1907
Las principales fuentes documentales sobre el ciclo fundacional de Buenos Aires son las de Ulrico Schmídel ${ }^{12}$ y Luis de Miranda ${ }^{13}$, miembros de la expedición de Mendoza; el largo poema de Martín del Barco Centenera ${ }^{14}$ y la crónica de Díaz de Guzmán ${ }^{15}$, a principios del XVII; y posteriormente algunos capítulos de fray Reginaldo de Lizárraga ${ }^{16}$, la Descripción e historia del Paraguay y del Rio de la Plata de Félix de Azara ${ }^{17}$, y algunos otros testimonios como el citado del padre Guevara ${ }^{18}$. Pero lo que nos interesa ahora es la recuperación literaria de todo ese material que forma parte insustituible de lo que Borges encerró en el título de aquel poema: «Fundación mítica de Buenos Aires».

El primer testimonio del que voy a ocuparme es la novela Lucía Miranda de Hugo Wast (seudónimo de Gustavo Martínez Zuviría) escrita en París entre 1927 y 1928. La obra podría enmarcarse en lo que Seymour Menton denomina «novela histórica tradicional», que se desarrolla en casi todos los países latinoamericanos, hasta mediados del siglo XX, y que es heredera de la narrativa histórica romántica del XIX. La novela de Wast transcurre en un momento que podríamos llamar «prefundacional», durante la exploración y conquista del vasto territorio del Río de la Plata, o Mar dulce, o Río de Solís, como también aparece nombrado en los documentos de la época.

La trama de la novela de Wast, se centra en el personaje de Lucía Miranda, esposa de Sebastián Hurtado, uno de los soldados que acompañó al navegante veneciano Sebastián Gaboto, fundador del fuerte de Sancti Spiritu, en la segunda expedición al Río de la Plata en 1526. Es interesante la elección de este personaje por parte de Wast para su acercamiento al pasado argentino, ya que más que a un referente histórico, responde claramente a un modelo literario. La historia de Lucía Miranda había aparecido por primera vez en el capítulo séptimo de la crónica de Díaz de Guzmán. Mucho se ha debatido sobre la procedencia de este relato, parece aceptado que Guzmán, como había hecho el Inca Garcilaso en sus Comentarios Reales, introdujo pequeñas parábolas o «casos historiales», para ilustrar su discurso: la aventura de «la Maldonada» y la leona, por ejemplo, que recoge un motivo sobradamente frecuentado por la cultura occidental ${ }^{19}$; y el de Lucía Miranda, que según De Angelis podría responder al tópico romancís- 
tico de Inés de Castro ${ }^{20}$. De nuevo la pugna entre la historia y la fábula ${ }^{21}$. El motivo de Lucía Miranda tiene además una prolongada formulación dentro de la tradición literaria argentina, desde la tragedia neoclásica de José Manuel Lavardén titulada Siripo 22 (1789) a las novelas románticas de Rosa Guerra en 1860 y Eduarda Mansilla en 1882, ambas bajo el título de Lucía Miranda ${ }^{23}$.

Fuera del «drama de amor», cuyos pormenores no son relevantes en este momento, lo que más nos interesa es la visión que tiene Hugo Wast de la empresa conquistadora española. Y esa visión en general es bastante complaciente, y en algunas ocasiones absolutamente idealizada, mucho más conservadora en este sentido que la de Lavardén, un siglo y medio atrás:

Miríadas de flamencos rosados cerníanse arriba de los mástiles, formando a las carabelas un dosel de púrpura.

La gente iba cantando, y las canciones españolas rodaban sobre las aguas y penetraban en los bosques profundos.

Y cuando por azar callaban todos a la vez, escuchaban la voz nueva, semejante a un idioma ignorado, de la tierra misteriosa y magnífica, una voz compuesta por el canto de pájaros nunca vistos y por el murmullo del viento en una selva jamás herida por un hacha de hierro.

Aquello era realmente un himno de América a la nación poderosa que engendraba corazones capaces de lanzarse a semejante aventura para descubrir un secreto guardado por los mares y por los siglos ${ }^{24}$.

En última instancia, la importancia de la obra de Wast estriba en que permite establecer una tradición en la reconstrucción del pasado colonial argentino que se remonta a las crónicas de la conquista y reaparece de forma recurrente a lo largo de los siglos XVIII, XIX y XX.

\section{NACIONALISMO E IDENTIDAD}

Nos aproximamos a una fecha crucial. En 1936, el intendente de Buenos Aires, Mariano de Vedia y Mitre, organiza un «ciclo de disertaciones histórico-literarias» bajo el título de Homenaje a Buenos Aires en el cuarto centenario de su fundación ${ }^{25}$. En las primeras décadas del siglo, algunos estudios ya habían abordado el período fundacional desde una

perspectiva crítica, me refiero, por ejemplo, a La ciudad indiana (1900) de Juan Agustín García o al Mendoza y Garay (1916) de Paul Groussac, herederos ambos del clásico estudio de Eduardo Madero (Historia del puerto de Buenos Aires, 1892). Sin embargo, aunque en el Homenaje... se alude a una presunta restitución de «la verdad histórica» ${ }^{26}$, el tono general de todo el volumen es bastante indulgente respecto a la acción colonizadora española y no esconde en determinadas ocasiones un sentimiento hispanófilo más que noto$\mathrm{rio}^{27}$.

Enrique Larreta, que presidió la Comisión Nacional para la conmemoración de dicha efemérides, contribuyó con dos títulos de inequívoca inspiración: Santa María del Buen Aire y Las dos fundaciones de Buenos Aires. No era la primera vez que Larreta dedicaba su atención al período colonial, en 1908, había publicado La gloria de don Ramiro. Una vida en tiempos de Felipe II. En toda la novela, según Amado Alonso, siguen funcionando «los resortes de conducta que la exaltación romántica quiso ver en la vida de los españoles ${ }^{28}$, aunque, a pesar de ser calificada por Lugones de «pegajosa hispanofilia», la obra de Larreta no cae en

20

En su edición de la Historia argentina... de Guzmán, ed. cit., pág. XXXIV.

21

Juan Agustín García en un artículo de 1922, «Nuestra incultura», subrayaba el pintoresquismo de la cultura popular argentina en lo relativo a los entresijos de la historia nacional: «Se preocupará poco [el argentino] del itinerario de los conquistadores; en cambio el episodio de Lucía Miranda, el cuento de la Maldonada, absorberá su atención». Cito por Lepoldo Zea (comp.), Pensamiento positivista latinoamericano, Caracas, Biblioteca Ayacucho, 1980, vol. 1, pág. 420.

22

Marcelino Menéndez Pelayo en su Historia de la poesía hispano-americana (Madrid, CSIC, 1948, vol. 2, pág. 327), consi- dera que la obra de Lavardén "es imitación de otra compuesta en lengua italiana por el jesuita valenciano D. Manuel Lassala...». Pedro Luis Barcia ("Las letras rioplatenses en el período de la llustración: Juan Baltasar Maciel y el conflicto de dos sistemas literarios», en Humanidades. Revista de la Universidad de Montevideo, año I, núm. 1, junio 2001, pág. 49) cita también la versión de Lassala (Manuel Lassala, Lucía Miranda: tragedia, Bologna, a San Tommaso D'Aquino, 1784) y añade otra anterior en inglés de Thomas Moore, Mangore, king of the Timbues, 1721.

23

Rosa Guerra, Lucía Miranda. Novela histórica, Buenos Aires, Imprenta Americana, 1860; Eduarda Mansilla de García, Lucía Miranda: novela histórica, Buenos Aires, Imprenta de Juan A. Alsina, 1882.
24

Hugo Wast, Lucía Miranda, Burgos, Editorial Aldecoa, 1945, págs. 53-54

25

V. AA., Homenaje a Buenos Aires en el cuarto centenario de su fundación, Buenos Aires, Municipalidad de la Ciudad de Buenos Aires, 1936.

26

Cf. Ricardo Levene, «La conquista de América y la expedición de don Pedro de Mendoza», en Homenaje a Buenos Aires..., op. cit., pág. 13.

27

"Venimos a rememorar un hecho insigne y a rehabilitar la memoria de un héroe. Hace hoy precisamente cuatro siglos que don Pedro de Mendoza ponía nombre, fundaba la población que hoy se llama como él la llamó y que evoca la empresa heroica $y$ la gloria de su fundador». Mariano de Vedia y Mitre, «Discurso del Intendente Municipal Dr. Mariano de Vedia y Mitre», ibidem, pág. 7.

28

Amado Alonso, Ensayo sobre la novela histórica. El modernismo en "La Gloria de don Ramiro", Madrid, Gredos, 1984, pág. 93

Ficciones fundacionales en la narrativa argentina del siglo $\mathrm{XX}$ PEDRO MENDIOLA OÑATE 


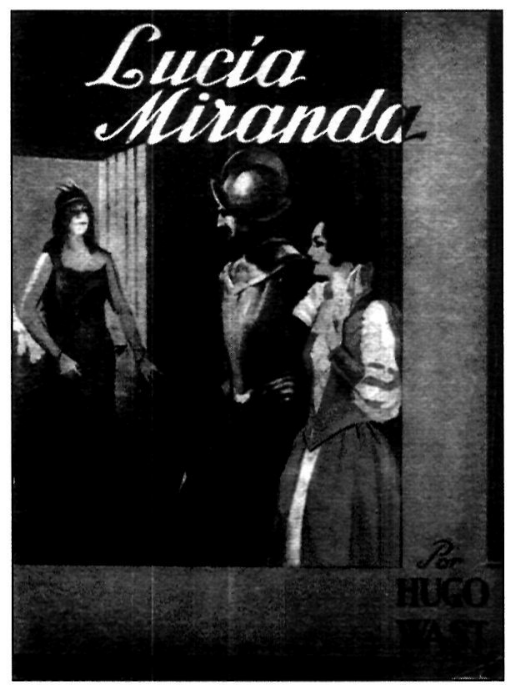

29

Enrique Larreta, "Autocrítica de Santa María del Buen Aire», publicada en $A B C$ de Madrid el 5 de diciembre de 1935 (recogido en Santa María del Buen Aire, Madrid, 1944, pág. 5). Tomo la cita de María Caballero, Novela histórica y postmodernidad en Manuel Mujica Láinez, Sevilla, Universidad de Sevilla, 2000, pág. 49 .

\section{0}

José Enrique Rodó, «La tradición intelectual argentina», en La tradición intelectual argentina, Buenos Aires, EUDEBA, 1968, pág. 12.

31

Enrique Larreta, Las dos fundaciones de Buenos Aires, ed. cit., págs. 145-146.

32

Ricardo Rojas, La restauración nacionalista. Crítica de la Educación Argentina y Bases para una Reforma en el Estudio de las Humanidades Modernas, Buenos Aires, A. Peña Lillo editor, 1971 (3. ${ }^{\circ}$ ed.), págs. 128-129

33

Roberto Levillier, Estampas virreinales americanas, Buenos Aires, Espasa-Calpe, 1947, pág. 9

Ficciones fundacionales en la narrativa argentina del siglo $\mathrm{XX}$ PEDRO MENDIOLA OÑATE ningún momento en la idealización del período colonial. Por el contrario, en Las dos fundaciones de Buenos Aires, Larreta reanima algunos aspectos del ciclo fundacional porteño, a través de una narración polifónica en la que las fuentes literarias e históricas se entreveran con la imaginación y la memoria del narrador, con el objetivo de forjar no una mitificación histórica sino una mitificación literaria:

Si aquellas empresas deslumbradoras pueden compararse por momentos con libros de caballerías, ésta de Mendoza, por su desaforada ilusión y áspero destino, aseméjase mucho al libro de Cervantes. Allí el Amadís; aquí el Quijote ${ }^{29}$.

Por eso, más que la vertiente épica, Larreta indaga el lado humano de la conquista del Plata, y nos dibuja al fundador no como un gran héroe, de brillante armadura y bruñidas armas, sino como un sobreviviente hambriento y enfermo, cargado de flaquezas y debilidades, sembrando las bases tal vez de una genealogía del carácter porteño, de la identidad espiritual argentina, como harían también desde diversos ángulos Martínez Estrada, Leopoldo Marechal o Scalabrini Ortiz. Casi puede verse a Pedro de Mendoza, ese hombre que está solo y espera, sentado en la esquina de Corrientes y Esmeralda.

Sin embargo, el discurso de Larreta se encamina resueltamente hacia otros derroteros. Comienza por reivindicar el pasado colonial argentino, frente a otros histórica y literariamente mejor trabados como los de Perú y México; y en esto replica, por ejemplo, a Rodó que había subrayado en 1903 la carencia en Argentina «del precedente de una cultura literaria dentro de la tradición de la colonia, como la había, con arraigo dos veces secular, en el Perú y en México» ${ }^{30}$. Pero pronto nos damos cuenta de que esa revisión de la historia nacional, no se hace en términos abstractos, sino que encubre una pretensión clara: la restitución del espíritu hispánico, encarnado en el pasado colonial, como elemento determinante del alma verdadera del pueblo argentino, en desmedro de otras aportaciones menos «homogéneas»:
Sería absurdo lamentarse ahora de que Buenos Aires no haya conservado el aspecto de otros tiempos. Sin embargo, se puede concebir una ciudad que hubiera sido como el desarrollo grandioso de la aldea de antaño. Se produjo la invasión «de todos los hombres del mundo». Imposible que el inmigrante al enriquecerse renunciara a la arquitectura de su país.

El mismo mal gusto, sostenido con unidad y firmeza de estilo, puede llegar a ofrecer interés estético. La peor de todas las fealdades: lo heterogéneo ${ }^{31}$.

En la exposición de Larreta brilla claramente el ideario nacionalista de los hombres del Centenario, del Manuel Gálvez de El diario de Gabriel Quiroga (1910) o El Solar de la raza (1913), del Manuel Ugarte de El porvenir de la América Española (1911), o del Ricardo Rojas de El alma española (1907), La restauración nacionalista (1909) o Blasón de Plata (1912), que vieron en la tradición hispánica un sólido cimiento sobre el que sustentar la nunca del todo consolidada identidad nacional. Son significativas, por ejemplo, las coincidencias de pensamiento entre las palabras de Larreta y algunas ideas vertidas en $\mathrm{La}$ restauración nacionalista de Rojas; un extenso ensayo, concebido en un principio como un informe sobre la educación en Argentina, en el que Rojas no sólo preconizaba la «restauración del pasado histórico» y la recuperación de las fuentes históricas coloniales, sino que advertía también del peligro que para la formación de una conciencia nacional argentina suponía la proliferación de otras tradiciones culturales como la itálica, que amenazaba con convertir a la Argentina en una "colonia italiana sin bandera» ${ }^{32}$.

Entreténgase el lector brevemente en este otro testimonio. En 1939, el historiador Roberto Levillier deslizaba a la imprenta sus $E$ stampas virreinales americanas, un simple «divertimento", según el autor, sin otro objetivo que el de «animar episodios que la cronología primitiva omitió en sus anales íntimos» ${ }^{33}$. La obra sitúa la acción entre la primera y la segunda fundación de Buenos Aires, momento de cierta indefinición geográfica en el que Buenos Aires permanece abandonada, y el territorio argentino es denominado indistintamente Argentina, Río de la Plata y Nueva Vizcaya. En esa situación, Hernando de Aguirre, hijo del conquistador Francisco de Aguirre (fundador de la ciudad de Santiago del Estero en 1553), trata de convencer al Gober- 
nador y capitán de las Provincias del Río de la Plata, Juan Ortiz de Zárate, de reedificar la desamparada ciudad de Buenos Aires. Sin embargo, Ortiz de Zárate albergaba la peregrina ocurrencia de sustituir la Buenos Aires de Pedro Mendoza por una ciudad llamada, nada menos, Zaratina de San Salvador ${ }^{34}$.

El propósito de Levillier, que había registrado el Archivo General de Indias y había publicado mil y un papeles referentes al período colonial argentino ${ }^{35}$, no difiere del resto de su producción histórica y literaria, vertebrada como en el título de una de sus obras por «la reconstrucción del pasado colonial»: «presentar unida la evolución de la vida múltiple de la colonia, con la evolución del tipo étnico», y establecer una «íntima continuidad entre la organización general de la colonia y la que poco a poco adquirió la nueva nación después de la independencia» ${ }^{36}$. Pero este empeño, loable según se mire, responde igualmente a una clara determinación ideológica que sigue corroborando ese creciente sentimiento hispánico y que en el ámbito histórico desarrollaron ampliamente Ricardo Levene, Rómulo Carbia, Torre Revello, Enrique de Gandía o el propio Levillier. Así se desprende de la presentación editorial de Estampas virreinales..., donde se declara que la obra de Levillier está destinada «a esclarecer las falsedades de la leyenda negra y ofrecer una exacta imagen de la obra de España en América» ${ }^{37}$. Coincidencia o no, la obra literaria de Levillier ha pasado al más plácido de los olvidos como pasó con aquella inverosímil Ciudad Zaratina.

\section{SUB-VERSIÓN DE LA HISTORIA}

Hasta el momento, hemos visto muy diferentes posturas frente al pasado pre-independentista argentino, que pasan sucesivamente de la negación a la reconstrucción, a la evocación y a la reivindicación. El desarrollo de la llamada «nueva novela histórica», a partir de la segunda mitad del siglo XX, sigue recurriendo abundantemente al periodo hispánico, pero con el fin de desmontar, subvertir y desacralizar los mitos asumidos, los oropeles de la, siempre enjuiciada, verdad histórica.

En este sentido, la obra de Manuel Mujica Láinez ejemplifica perfectamente ese tránsito entre la narrativa histórica tradicional y la nueva novela histórica. En la década del cuarenta, Mujica Láinez publica tres títulos que la

crítica ha considerado genéricamente como el «ciclo de la fundación de Buenos Aires». Se trata del largo poema titulado Canto a Buenos Aires (1943) y los libros de relatos Aqui vivieron (1949) y Misteriosa Buenos Aires (1950). Los tres libros se remontan al período fundacional, estableciendo un continuo histórico que surge de la colonia y desemboca en el siglo XX.

En estos escritos, la visión de Mujica Láinez, que había participado en el citado Homenaje a Buenos Aires de 1936 y que en 1938 había publicado una primera novela histórica sobre el período virreinal (Don Galaz de Buenos Aires), se encuentra todavía la influencia de Larreta: la epopeya del hambre, el trasfondo épico, el perfil cervantino de los conquistadores:

Un hidalgo de Argamasilla, lector famoso de libros de caballerías, iba con ellos. Iba con ellos también un paladín de quien se dijo que ganaba batallas después de muerto y realizaba de ese modo la bella leyenda. Los hombres de Mendoza y de Irala no los vieron nunca. Pero delante de los expedicionarios, en las horas más acerbas, entre el polvo y las espinas y el silbar de los dardos y el relincho de las cabalgaduras sudorosas, galopó la sombra escuálida de Rocinante y tremolaron las banderas y se alzaron las lanzas del $\mathrm{Cid}^{33}$.

Sin embargo, Aqui vivieron, que lleva el subtítulo de «Historias de una Quinta de San Isidro 1583-1924», introduce una variante significativa: el autor se acerca al momento de la fundación de una manera tangencial: la acción se inicia en 1583, tres años después de la se-

34

Cf. Ángel Rosenblat, Estudios dedicados a la Argentina, Caracas, Monte Ávila, 1984, pág. 20.

\section{5}

Orígenes argentinos, París, Ed. Fasquelle, 1912; Correspondencia de la ciudad de Buenos Ayres con los Reyes de España. 1588-1615, Buenos Aires, Municipalidad de Buenos Aires, 1915; Correspondencia de oficiales Reales de Hacienda del Río de La Plata con los Reyes de
España. 1540-1596, Buenos Aires, Municipalidad de Buenos Aires, 1915; Antecedentes de Política Económica del Río de La Plata, Buenos Aires, Municipalidad de Buenos Aires, 1915, 2 tomos; El licenciado Matienzo loidor de la audiencia de Charcas 1561-1579): inspirador de la segunda fundación de Buenos Aires, Madrid, Imp. de Juan Pueyo, 1919

36

Roberto Levillier, La reconstrucción del pasado colonial, Bue- nos Aires, «Librería Mendesky» de Augusto Sabourin e hijo, 1917, pág. 6.

37

Estampas virreinales americanas, op. cit. Declaración similar a otras reveladas por Levillier respecto a su obra historiográfica: «Es, pues, ese pasado el que debe reconstruirse en toda su magnitud para intensificar en los americanos sentimientos de amor a la raza, al suelo, y a los progenitores; para hacer justicia plena a la obra de civilización de España, para coadyuvar, al movimiento de simpatía y de cariño, que de un lado al otro del Atlántico, arrastra a los hijos de la América de hoy hacia la raza creadora de la América de ayer» (Roberto Levillier, «Proyecto de creación de un Centro Internacional de Investigaciones Históricas y discusión del mismo en el Congreso de Historia y Geografía de Sevilla-abril 1914», en La reconstrucción del pasado colonial, op. cit., pág. 26).

\section{8}

Manuel Mujica Láinez, «Buenos Aires en el siglo XVII», en Homenaje a Buenos Aires en el cuarto centenario de su fundación, ed. cit., págs. 438-439.
Ficciones fundacionales en la narrativa argentina del siglo $X X$ PEDRO MENDIOLA OÑATE 
Cf. María Caballero, op. cit, págs. 115-119.

40

Simpática alusión al famoso poema de Baldomero Fernández Moreno «Setenta balcones y ninguna flor». Manuel Mujica Láinez, De milagros y de melancolias, Buenos Aires, Editorial Sudamericana, 1969, pág. 44.

\section{1}

Fustel de Coulanges, La ciudad antigua, ed. de J. F. Yvars, Barcelona, Ediciones Península, 1984, pág. 157.

\section{2}

Manuel Mujica Láinez, «El sueño del capitán Ascasusso, San Isidro cumple hoy 200 años», en La Nación, Buenos Aires, 14 de octubre de 1956. Cit. por Sorkunde Frances Vidal, La narrativa de Mujica Láinez, Bilbao, Universidad del País Vasco, 1986, pág. 41.

43

Manuel Mujica Láinez, De milagros y de melancolias, ed. cit., pág. 37 .

\section{4}

Gabriel García Márquez, Cien años de soledad, Barcelona, RBA Editores, 1994, pág. 15.

\section{5}

Cf. "Manifiesto Martín Fierro", en Martín Fierro, 2. ${ }^{\circ}$ época, año I, núm. 4, mayo 5 de 1924.

46

Daniel Moyano, El trino del diablo, Barcelona, Ediciones $B$, 1988, págs. 9-10 gunda fundación; se localiza no en Buenos Aires, sino en San Isidro, una población cercana a la capital; a Garay, el segundo fundador, sólo se le muestra de lejos, visto desde la ribera, cuando éste abandona ya la ciudad, definitivamente fundada, camino de Santa Fe; y por último, el protagonismo recae sobre una esclava africana y un indio querandí. Es decir, es digamos una historia marginal de la fundación.

En una novela bastante posterior, De milagros y de melancolías (1968), la subversión histórica se plantea ya en términos absolutos. En ella, a decir de María Caballero, el autor ensaya una «parodia e inversión de los mitos de la conquista americana ${ }^{39}$. El referente histórico aparece ya totalmente ficcionalizado: los personajes, la topografía, incluso todo un entramado bibliográfico, son fruto de la invención. Aunque son perceptibles ciertos guiños que aluden a lo que podríamos denominar la memoria colectiva porteña:

No brotaba allí más vegetación que los gigantescos cardones erizados de espinas, verdosos, negruzcos; [...] una inmensidad de candelabros que alzaban los brazos cubiertos de púas inexorables; a veces solitarios; a veces concentrados en miles de miembros que imploraban, inmóviles, el favor de una lluvia; a veces en hileras de sesenta, de setenta cardones y ninguna flor ${ }^{+0}$.

El fundador, Don Nufrio, proyecta la fundación de San Francisco de Apricotina del Milagro, y todo el complejo rito fundacional es sistemáticamente ridiculizado, reducido al absurdo. Casi parece estar desmontando uno por uno todos los elementos que, según Fustel de Coulanges, caracterizaban tradicionalmente «el culto del fundador»:

El fundador era el hombre que consumaba el acto religioso sin el cual no podía existir la ciudad; era quien colocaba el hogar donde había de arder eternamente el fuego sagrado, quien con sus oraciones y sus ritos llamaba a los dioses y los asociaba por siempre a la nueva ciudad. Podemos, pues, concebir el respeto que debía tributarse a este hombre sagrado que, vivo, se tenía por autor del culto y padre de la ciudad, y, muerto, se convertía en un antepasado común a todas las generaciones que se sucedían; era para la ciudad lo que el primer antepasado para la familia, un lar familiar ${ }^{41}$.

Es el triunfo definitivo de la fábula sobre Ficciones fundacionales en la narrativa argentina del siglo $X X$ PEDRO MENDIOLA ONATE ria. Es una forma de la verdad acaso más profunda, y sobre todo más sutil, que la que nos empeñamos en considerar la verdad verdadera ${ }^{42}$. Pretensión de verdad que el fundador demanda insistentemente al cronista de la empresa, el capitán Diego Cintillo, con la irónica fórmula: «ajustaos, Cintillo» ${ }^{43}$.

En estas novelas, el periodo colonial comienza a ser asumido como un elemento propio, como algo natural, casi innato, de la esencia americana; como aquel destartalado galeón español «rodeado de helechos y palmeras, blanco y polvoriento en la silenciosa luz de la mañana», que García Márquez colocara en medio de la selva de Macondo, ocupando «un ámbito propio, un espacio de soledad y olvido, vedado a los vicios del tiempo ${ }^{44}$; acaso el penúltimo vestigio de una civilización perdida. Es una manera de acercarse al pasado para mostrarnos los dobleces, las contradicciones, las falsas utopías de la pretendida verdad histórica, como quien hojea un álbum de retratos familiar, parafraseando a los poetas de la revista Martín Fierro, «para descubrirse a través de un antepasado... o reírse de su cuello y de su corbata ${ }^{45}$. Esta misma formulación es la que va a prevalecer en las posteriores recreaciones del pasado colonial en la literatura argentina, en Pedro Orgambide, en Abel Posse, en Juan José Saer o en Daniel Moyano.

Con Daniel Moyano, precisamente, puede cerrarse el círculo del discurso fundacional. Moyano abre su novela El trino del diablo (1974), con un primer capítulo titulado «Sobre el arte de fundar ciudades». Allí se ríe también Moyano de toda la tramoya fundacional:

Sin pérdida de tiempo ordenó desmontar el bosque circundante para dar paso a la futura Plaza Mayor de la ciudad, en cuyo centro, cuando todavía no habían acabado de recoger los troncos y las ramas de los árboles caídos, ya estaba Ramírez izando el estandarte real diciendo «España» repetidamente, ya iba con pasos de danza dando golpes de mandoble en esos aires vírgenes a diestra y siniestra, ya ordenaba que el padre Francisco improvisase un altar para la primera misa, ya estaba señalando con sus pasos el cuadrado de la plaza, cortando hierbas y diseñando la jurisdicción, ya estampando su rúbrica al pie del acta redactada por el notario, ya atronando el aire con los estampidos de los arcabuces para comunicarles a los indios, escondidos tras las piedras mirando asombrados la extraña ceremonia, que era muy peligroso oponerse a la fundación que acababa de consumarse ${ }^{46}$. 
La última broma de Moyano, la última vuelta de tuerca al mito fundacional, se cifra cuando los topógrafos informan al fundador que han equivocado sus cálculos y le aconsejan «desfundar» la ciudad y buscar un lugar más conveniente algunas leguas al norte. Sin embargo, Ramírez de Velazco, resignado, decide aceptar los infortunios que de la fundación se deriven:

-Lástima de Rioja -dijo Ramírez vertiendo una lágrima fundacional cuando el notario terminó de redactar la enmienda-; lástima de tierra castigada y asimismo olvidada ${ }^{47}$.

Podríamos citar algunos otros títulos que abordan el período fundacional rioplatense desde muy diversos puntos de vista, pero he trazado este recorrido porque creo que da una idea bastante clara de las distintas formulaciones y propósitos con que la narrativa argentina del siglo XX se acercó al pasado colonial.

Me gustaría acabar con una pequeña broma literaria. Se trata de una obra muy breve, una «fantasía humorística» del dramaturgo, letrista de tango y cineasta de origen vasco Luis Bayón Herrera, que lleva por título Doña Maria del Buen Aire y fue publicada en 1936, el año del cuarto centenario. La obra, en la que se advierte que no es una versión bufa del susodicho drama de Larreta, está plagada de premeditados y divertidos anacronismos, y tiene la gracia de establecer un puente temporal entre la ciudad inicial y la ciudad contemporánea, sin la pompa y la ceremonia que le dedicaron los literatos del momento: los indios, por ejemplo, hablan en lunfardo y bailan tango, y Pedro de Mendoza en el mismo acto fundacional establece las bases de la ciudad futura:
¡Oh dejadme soñar! ¡Ya la estoy viendo!
(...)
Ya la veo crecer vertiginosa
sobre firmes cimientos,
ya veo transformarse cada choza...
en una casa de departamentos.
Ya son calles los campos primitivos; ya los bosques, jardines señoriales, Ya veo inaugurar las diagonales... y hasta veo chocar los colectivos ${ }^{48}$.

47

Ibidem, pág. 12

48

Luis Bayón Herrera, Doña María del Buen Aire, en Nuestro Teatro, Buenos Aires, Añol, núm. 25, 10 de junio de 1936, págs. 18-19. 